\title{
Coulisses
}

Revue de théâtre

\section{Die Offenbarung des Johanes - L'Apocalypse de Jean par le théâtre universitaire de Cologne}

Rédaction

\section{(2) OpenEdition}

\section{Journals}

Édition électronique

URL : http://journals.openedition.org/coulisses/1637

DOI : $10.4000 /$ coulisses. 1637

ISSN : 2546-9460

Éditeur

Presses universitaires de Franche-Comté

\section{Édition imprimée}

Date de publication : 1 février 1991

Pagination : 25-26

ISSN : 1150-594X

\section{Référence électronique}

Rédaction, «Die Offenbarung des Johanes - L'Apocalypse de Jean par le théâtre universitaire de Cologne », Coulisses [En ligne], 3 | Hiver 1991, mis en ligne le 04 juillet 2017, consulté le 26 octobre 2019. URL : http://journals.openedition.org/coulisses/1637; DOI : 10.4000/coulisses.1637

Ce document a été généré automatiquement le 26 octobre 2019.

Coulisses 


\title{
Die Offenbarung des Johanes - L'Apocalypse de Jean par le théâtre universitaire de Cologne
}

\author{
Rédaction
}

\section{Les intentions du metteur en scène}

1 La mise en scène de cette partie très controversée de la Bible qu'est l'Apocalypse a pour but d'essayer d'approcher le texte avec des moyens empruntés tantôt au théâtre, tantôt à la musique, tantôt à la voix.

2 Le Prophète Jean a une vision? un rêve? une transe? de la destruction finale du monde. La fascination mais aussi l'horreur inspirées par cette parfaite mécanique de destruction ont constitué le point de départ de notre travail.

3 Jean lui-même est devenu le centre de nos préoccupations. Son rêve de la Nouvelle Jérusalem est si illusoire qu'on en arrive à se demander s'il est digne d'efforts.

4 Il n'apparaît à aucun moment de la mise en scène. Les sept autres personnages que nous rencontrons s'expliquent, aujourd'hui ? demain? avec ce texte.

5 L'Apocalypse décrit la destruction du monde, dans le texte de la Bible, il est beaucoup question de l'ouïe, de la perception auditive. C'est pourquoi nous avons choisi de placer au premier plan le travail sur le son : la langue, le bruit, le silence. Nous voulions faire peser cette atmosphère d'apocalypse à travers le musique, les mots psalmodiés sans pour autant renoncer tout à fait aux effets visuels. 


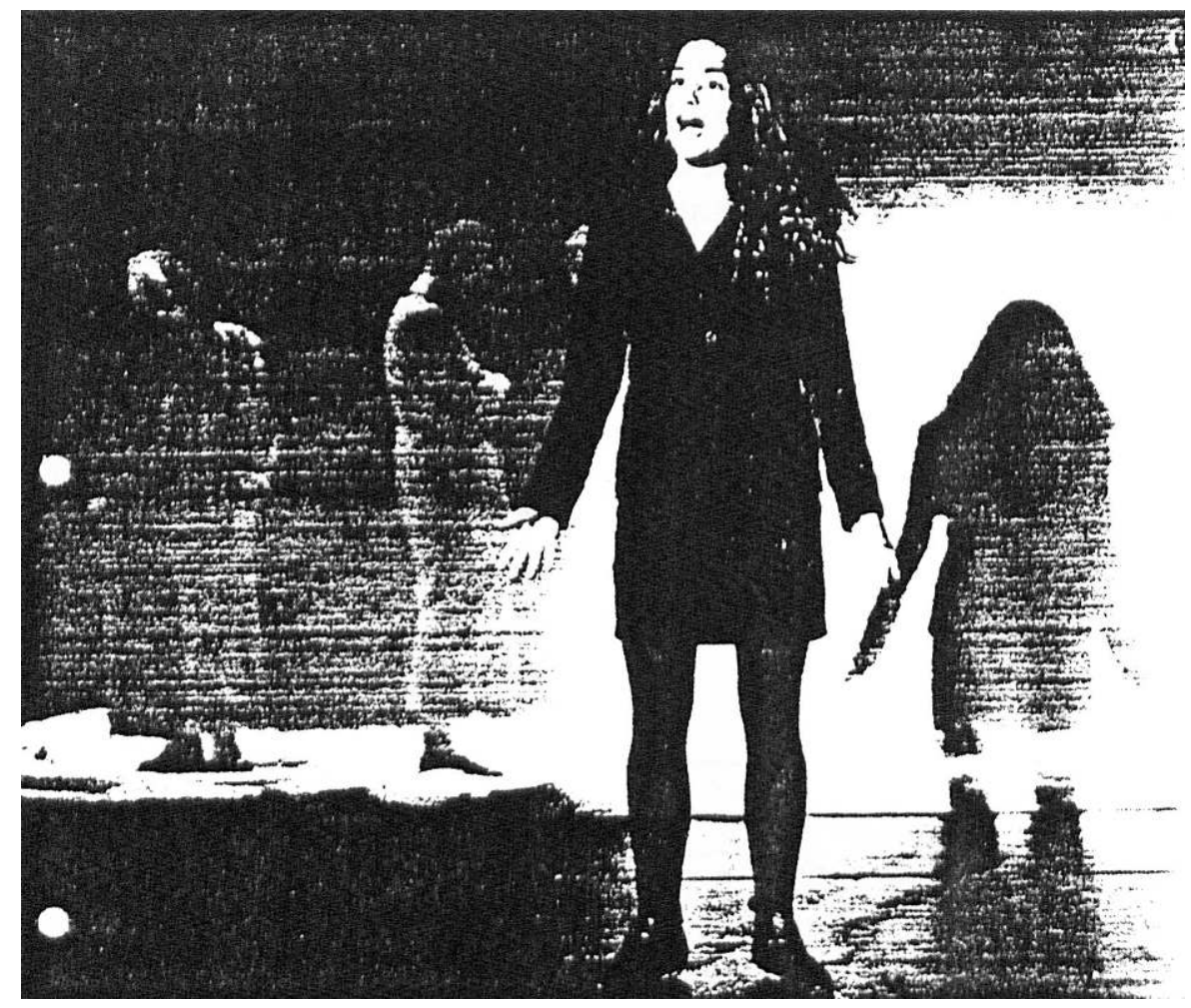

\section{Impressions}

De la force rêvent les faibles,

de la victoire rêvent les perdants,

de la vie éternelle rêvent les morts-vivants,

du pouvoir rêvent les impuissants, les évanouis.

6 Comme le bouquet final d'un feu d'artifice, L'Apocalypse selon saint Jean, qui clôturait les premières rencontres internationales, restera un des plus forts souvenirs de cette semaine. Les dix premières minutes établissent le rythme qui sera maintenu durant tout la durée du spectacle : dans l'obscurité, des voix issues de toutes parts, se heurtent, rebondissent, éclatent... Et alors, 1a lumière arrive... Chaque voix, chaque phrase, chaque mot est lancé, rattrapé, repris, se mêle à d'autres paroles, pour former un formidable écho, une harmonie admirablement orchestrée, une symphonie soutenue par des effets simples, dans une sobriété à l'étonnante efficacité.

7 Les dialogues s'intègrent de façon si remarquable à cet ensemble, que la barrière linguistique ne fait en rien obstacle à l'émotion, qui étreint le spectateur, prisonnier de ses sensations.

8 Le groupe forme une entité de laquelle il tire solidité, crédibilité et force. Peu importe la langue pour imaginer, sentir, éprouver... Ce ne sont pas des discours, ce ne sont pas des chants... c'est une musique, une harmonie vocale qui s'élève et prend rapidement le pas sur les quelques simples percussions qui grondent au début du spectacle.

9 On en sort bouleversé, ému, émerveillé... à quoi bon chercher des mots pour exprimer ce qu'ils nous ont fait ressentir sans y avoir recours? 